\title{
A Review of Mortality Risk Prediction Models in Smartphone Applications
}

\author{
Nino Fijačko ${ }^{1}$ D Ruth Masterson Creber $^{2} \cdot$ Lucija Gosak $^{3} \cdot$ Primož Kocbek $^{3} \cdot$ Leona Cilar $^{3} \cdot$ Peter Creber $^{4}$. \\ Gregor Štiglic ${ }^{5}$
}

Received: 11 August 2020 / Accepted: 27 September 2021 / Published online: 4 November 2021

(c) The Author(s), under exclusive licence to Springer Science+Business Media, LLC, part of Springer Nature 2021

\begin{abstract}
Healthcare professionals in healthcare systems need access to freely available, real-time, evidence-based mortality risk prediction smartphone applications to facilitate resource allocation. The objective of this study is to evaluate the quality of smartphone mobile health applications that include mortality prediction models, and corresponding information quality.We conducted a systematic review of commercially available smartphone applications in Google Play for Android, and iTunes for iOS smartphone applications. We performed initial screening, data extraction, and rated smartphone application quality using the Mobile Application Rating Scale: user version (uMARS). The information quality of smartphone applications was evaluated using two patient vignettes, representing low and high risk of mortality, based on critical care data from the Medical Information Mart for Intensive Care (MIMIC) III database.Out of 3051 evaluated smartphone applications, 33 met our final inclusion criteria. We identified 21 discrete mortality risk prediction models in smartphone applications. The most common mortality predicting models were Sequential Organ Failure Assessment (SOFA) $(n=15)$ and Acute Physiology and Clinical Health Assessment II $(n=13)$. The smartphone applications with the highest quality uMARS scores were Observation-NEWS 2 (4.64) for iOS smartphones, and MDCalc Medical Calculator (4.75) for Android smartphones. All SOFA-based smartphone applications provided consistent information quality with the original SOFA model for both the low and high-risk patient vignettes. We identified freely available, high-quality mortality risk prediction smartphone applications that can be used by healthcare professionals to make evidence-based decisions in critical care environments.
\end{abstract}

Keywords Severity of illness index $\cdot$ Hospital mortality $\cdot$ Mobile applications $\cdot$ Intensive care units

This article is part of the Topical Collection on Mobile \& Wireless Health

Nino Fijačko

nino.fijacko@um.si

1 Faculty of Health Sciences, University of Maribor, Zitna 15, Maribor, Slovenia

2 Department of Population Health Sciences, Division of Health Informatics, Weill Cornell Medicine, New York, NY, USA

3 Faculty of Health Sciences, University of Maribor, Maribor, Slovenia

4 Department of Respiratory Medicine, North Bristol NHS Trust, Bristol, UK

5 Faculty of Health Sciences and Faculty of Electrical Engineering and Computer Science, University of Maribor, Maribor, Slovenia

\section{Introduction}

Critical care is a complex and multidisciplinary specialty designed to care for patients with critical illnesses [1]. In intensive care units (ICU), healthcare professionals use mortality prediction models (MPMs) to triage patients [2-4], quantify the risk of sepsis and death [5, 6], and to estimate the cost of medical treatment [7-9]. MPMs are also used to prognosticate weaning from ventilators, length of ICU stay, mortality, and rate of recovery [10-15]. The MPM algorithms use physiologic measures [16] within $24 \mathrm{~h}$ of admission into the ICU [17] to calculate a risk score $[18,19]$. In combination with other patient-level variables, MPMs help healthcare professionals identify patients who will likely need additional intensive care support $[20,21]$. The three most common MPMs are: Acute Physiology and Clinical Health 
Assessment (APACHE), Sequential Organ Failure Assessment (SOFA), and Simplified Acute Physiology Assessment (SAPS) [5, 6]. The choice of MPM depends on the ease of use, effectiveness and reliability in the critical care environment [17].

Advances in point of care technologies, including smartphones [22] have played a key role in advancing access to healthcare information at the bedside [13], with critical care medicine at the forefront of these advances [23]. Healthcare professionals have been increasingly using smartphone applications (apps) in practice to provide users easier and faster real-time access to different models, to enhance decision making [24, 25], and assist in patient monitoring, counseling, data collection, and documentation [26]. In many countries that do not have access to electronic medical records (EMR) that automatically calculate MPM scores, healthcare professionals are using their smartphones to calculate these risk scores using apps [27-29].

The rapid global spread of COVID-19 has made smartphone-based MPM models increasingly relevant, especially as hospitals around the world converted operating rooms and medical units to intensive care units to handle patient volume [30-32]. Using stand-alone apps for risk prediction can support healthcare professionals who are providing inpatient care for patients [30-34], especially in the ICUs. Given the shortage of resources and increased risk of sepsis and death, the use of MPMs by healthcare professionals can facilitate clinical decision making $[5,6]$. In this systematic review of commercially available apps, we evaluated both overall quality and information quality of MPMs.

\section{Methods}

\section{Stage 1: Selection of the search strategy}

The Population Intervention Comparison Output (PICO) [35] framework was used to develop the research question. Population was ICU professionals, the intervention was MPMs in apps for critically ill patients in ICUs, and the output was information quality of MPMs in appsthere was no comparison in this study. Reporting for this systematic review followed Preferred Reporting Items for Systematic Reviews and Meta-Analyses (PRISMA) recommendations [36]. We used the following search terms: "ICU mortality", "mortality scoring system", "APACHE", "SOFA", "SAPS", "NEWS", "MODS", "LODS" and "medical calculator" for identifying MPMs in apps. Inclusion criteria included being freely available and in English. Apps were excluded if they could not be identified by the name, icon, or description, and require in-app purchases for the MPM.

\section{Stage 2: Screening and selection of the apps}

We conducted the first screening of apps in January 2020, and the secondary screening of apps in June 2020. Each keyword was used separately in Google Play and iTunes. We used iPadium [37] as a simulator for apps in the iTunes stores to be able to conduct the evaluations on a desktop computer. Duplicate apps from each search term in the smartphone app store and simulator were removed after they were copied into Excel spreadsheets independently by two authors (NF, LG). A third author was available for a discussion to help resolve disagreements in scores (GS). Apps which met inclusion criteria were downloaded and evaluated on a Samsung Galaxy S8 phone (Android 9.0) and iPhone 7 (iOS 12.3.1). The apps were sorted into two groups based on whether they included single or multiple MPM medical calculators.

\section{Stage 3: Evaluation of the quality of the overall apps}

The quality of apps was evaluated with the Mobile Application Rating Scale: user version (uMARS) [38] by two ICU nurses with over five years of critical care experience. The uMARS contains four objective quality scales: engagement, functionality, aesthetics, information quality, and one subjective quality assessment, all of which are graded on a five-point scale. The subjective quality and perceived impact of uMARS was not calculated. Interrater reliability was computed using $\mathrm{R}$ version 3.6.0 [39].

\section{Stage 4: Evaluation of apps provided information quality}

We used the freely available Medical Information Mart for Intensive Care III (MIMIC III), version 1.3 [40], which contains over 10 years (2001-2012) of de-identified critical care data from 46,520 ICU patients at Beth Israel Deaconess in Boston. Using the MIMIC III database, we developed two patient vignettes representing low and high risk of mortality based on SOFA scores. The SOFA MPM has six different scores, ranging from 0 to 4 for each organ system (respiratory, cardiovascular, hepatic, coagulation, renal, and neurological) [41]. The low-risk patient vignette had a SOFA score for each organ system from 0 to 2, and the high-risk vignette who had a SOFA score of 2 to 4 for 
each organ system. The data were analysed using $\mathrm{R}$, version 3.6.0 [39].

\section{Results}

As reported in our PRISMA flow diagram, we identified 3051 apps. After removing duplicates between keywords, 2758 apps remained. Based on pre-specified exclusion criteria (e.g., inappropriate name, icon, imagery, and images), we excluded 2690 apps. We added 5 apps after secondary app screening. After downloading and testing apps, a total of 33 apps were included in the final analysis (Fig. 1 and Table 1). Inter-rater reliability between raters for the uMARS was acceptable (reviewer one vs. reviewer two; Kalpha $=0.89$ ).

The quality of apps was evaluated using a standardized methodology, including the uMARS tool, and the overall uMARS app quality score was 3.66 $(\mathrm{SD}=0.65)$, which is considered as a moderate overall quality in comparison to the other studies [42-46]. Overall, $33.3 \%(n=11)$ of the apps were developed by small or medium-sized enterprises, $6.1 \%(n=2)$ by healthcare-related agencies, and $3 \%(n=1)$ by an educational organization (Table 1). Apps developed by individuals had lower overall quality, compared to apps developed by enterprises, educational or healthcare institutions $(\mathrm{M}=3.40 ; \mathrm{SD}=0.52$ vs. $\mathrm{M}=3.88$; $\mathrm{SD}=0.68 ; \mathrm{p}=0.001)$. The top-rated app was MDCalc Medical Calculator (4.75), which also had high ratings across all four domains.

We identified 21 different MPMs in apps. The most common MPMs in apps were SOFA $(n=15)$ and APACHE II $(n=13)$ (Fig. 2).

Less than a half of the apps $(n=13)$ included multiple MPM calculators (e.g., Nursing calculator with SOFA and MEWS $)$ and the others $(n=20)$, included a single MPM calculator. Two apps, MDCalc Medical Calculator and Doctor Calci included a total of 10 different MPMs (Table 2). Single MPM medical calculators had a lower mean app quality score $(\mathrm{M}=3.37 ; \mathrm{SD}=0.57 ; \mathrm{p}=0.002)$ compared to multiple MPM medical calculators $(\mathrm{M}=4.03 ; \mathrm{SD}=0.52)$.

Table 3 represents a list of 23 clinical variables in SOFAbased apps $(n=15)$. Variables were divided into six organ systems, as described by Vincent and colleagues in the SOFA validation study [41]. The lowest number of included variables in apps was 6 (e.g., app 3: SOFA), and the highest was 15 (e.g., app 24: Medical Calculators). Clinical data were most commonly inserted into the SOFA-based app using either a drop-down menu, or they were selected from a pre-populated list.
We evaluated the information quality of each of the SOFA-based apps against the low and high-risk vignettes, where low-risk vignette had a count of 6 points on the SOFA score and the high-risk vignette had a count of 18 points on the SOFA score (Table 4). There was greater variation (from $<10 \%$ to $<33 \%$ ) in the risk of mortality in the lower risk vignette (Table 5).

\section{Discussion}

Healthcare professionals need accurate, real-time, high quality information to make medical decisions for the most vulnerable patients in critical care environments. Many hospitals worldwide do not have EMRs, which calculate mortality risk prediction; therefore, smartphonebased MPMs are commonly used in clinical practice to predict hospital mortality [27-29]. This study systematically reviewed both the overall app quality and information quality of MPMs in apps.

Based on the overall uMARS quality assessment, the MPM apps provided moderate information quality. The most commonly downloaded app, MDcalc medical calculator, also had the highest quality rating and the most comprehensive, evidence-based MPM information. The highest rated apps had better visual information and incorporated high-quality scientific evidence [67, 68]. Most apps for mortality prediction are designed to optimize speed and minimize manual data entry (e.g., numeric text input) by using drop-down menus or choosing from a pre-populated list. The limitation of pre-populated values is that they may not include some value ranges, or they may not enable the functionality to toggle between metric and imperials units [69]. For example, MDCalc Medical Calculator resolved this problem by including a choice between units and providing additional alerts for healthcare professionals to check the input values. Relevant to protecting patient privacy, none of the apps included personally identifiable information.

To evaluate information quality, we used the SOFA score, because, in this review, it was the most widely used MPM across all of the apps. The apps generate a SOFA score and percentage for ICU mortality risk, which healthcare professionals interpret and use for medical decision making. When the quality of the MPM apps was evaluated against the two vignettes, the consistency of the app generated a high risk of mortality for the sicker patient and consistent scores for the lower risk patient, but with variability in the risk of mortality. We speculated that the discrepancies were due to differences in mortality algorithms and 


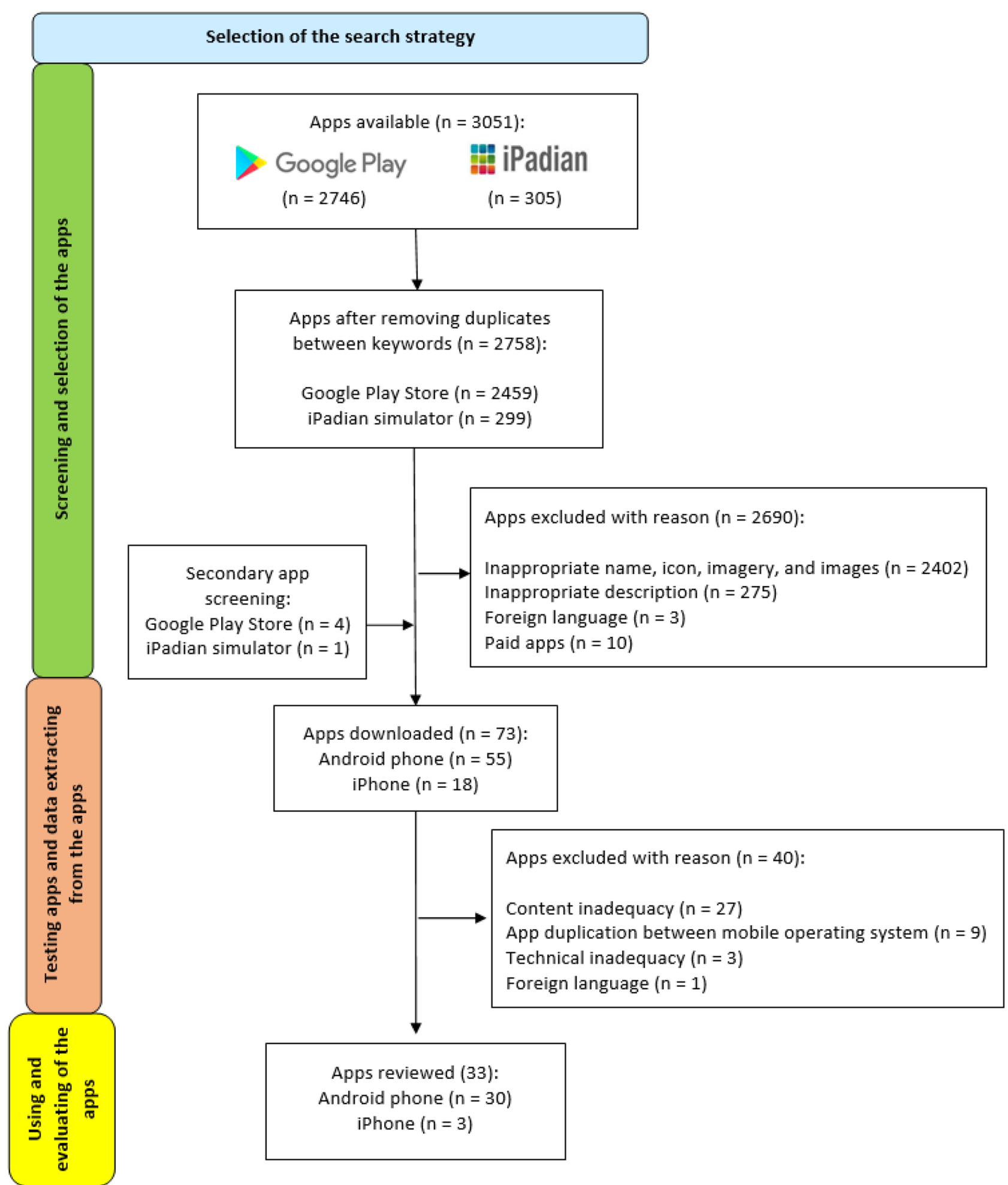

Fig. 1 PRISMA flow diagram 
Table 1 Descriptive characteristics of included apps and uMARS app quality scores

\begin{tabular}{|c|c|c|c|c|}
\hline \multicolumn{4}{|l|}{ Descriptive characteristics } & \multirow{2}{*}{$\begin{array}{l}\text { uMARS sections } \\
\text { Engagement (mean score) }\end{array}$} \\
\hline Name of apps & Short name & MOS & App origin & \\
\hline $\begin{array}{l}\text { 1. SOFA-Sepsis-related Organ Failure } \\
\text { Assessment }\end{array}$ & App 1 & AND & Individuals & 2.80 \\
\hline 2. Apache II Score & App 2 & AND & Individuals & 3.30 \\
\hline 3. SOFA & App 3 & AND & Individuals & 3.40 \\
\hline 4. SOFA Score & App 4 & AND & Individuals & 3.40 \\
\hline 5. SAPS 3 Calc & App 5 & AND & Individuals & 3.50 \\
\hline 6. Sepsis Score: SOFA Calculator & App 6 & AND & Individuals & 3.40 \\
\hline 7. qSOFA Score calculator & App 7 & AND & Individuals & 3.20 \\
\hline 8. qSOFA Score Calculator & App 8 & AND & Individuals & 3.20 \\
\hline 9. SOFA score & App 9 & AND & Individuals & 3.30 \\
\hline 10. MEWS (Modified Early Warning Score) & App 10 & AND & Individuals & 2.60 \\
\hline 11. NEWS2 Chart & App 11 & AND & Individuals & 2.80 \\
\hline 12. NEWS score & App 12 & AND & Individuals & 2.70 \\
\hline $\begin{array}{l}\text { 13. NEWS 2-National Early Warning Score } \\
2017\end{array}$ & App 13 & AND & Individuals & 2.70 \\
\hline 14. Observation-NEWS 2 & App 14 & iOS & Small and Medium-sized Enterprises & 3.70 \\
\hline 15. RRAPID & App 15 & iOS & Educational Organizations & 2.50 \\
\hline 16. MEWS & App 16 & $\mathrm{iOS}$ & Individuals & 2.90 \\
\hline 17. NEWS Wales & App 17 & AND & Healthcare related Agency & $\begin{array}{l}2.80 \\
2.80\end{array}$ \\
\hline 18. Medical Formulas & App 18 & AND & Individuals & 3.60 \\
\hline 19. EP Mobile & App 19 & AND & Small and Medium-sized Enterprises & 3.50 \\
\hline 20. MedCal Lite Fastest Medical Calculator & App 20 & AND & Individuals & 3.90 \\
\hline 21. Nursing Calculator & App 21 & AND & Individuals & 2.90 \\
\hline 22. Nursing & App 22 & AND & Individuals & 3.40 \\
\hline 23. Doctor Calci & App 23 & AND & Small and Medium-sized Enterprises & 3.60 \\
\hline 24. Medical Calculators & App 24 & AND & Individuals & 4.30 \\
\hline 25. NEWS \& SEPSIS SCREENING & App 25 & AND & Healthcare related Agency & 3.50 \\
\hline 26. Calculate by QxMD & App 26 & AND & Small and Medium-sized Enterprises & 3.60 \\
\hline 27. Coly ICU & App 27 & AND & Small and Medium-sized Enterprises & 3.30 \\
\hline 28. 3C Critical Care Calculators & App 28 & AND & Small and Medium-sized Enterprises & 3.40 \\
\hline 29. MDCalc Medical Calculator & App 29 & AND & Small and Medium-sized Enterprises & 4.30 \\
\hline 30. MediCalc $®$ & App 30 & AND & Small and Medium-sized Enterprises & 4.10 \\
\hline 31. SEPSIS 3 & App 31 & AND & Small and Medium-sized Enterprises & 3.90 \\
\hline 32. Sepsis Clinical Guide & App 32 & AND & Small and Medium-sized Enterprises & 3.90 \\
\hline 33. NCalc & App 33 & AND & Small and Medium-sized Enterprises & 2.90 \\
\hline \multicolumn{3}{|l|}{$\mathrm{MOS}=$ mobile operating system; $\mathrm{AND}=$ Android } & $\begin{array}{l}\text { Total mean } \\
\text { (SD) }\end{array}$ & $\begin{array}{l}3.35 \\
(0.48)\end{array}$ \\
\hline
\end{tabular}

Descriptive characteristics

\begin{tabular}{lllll}
\hline Name of apps & $\begin{array}{l}\text { Functionality } \\
\text { (mean score) }\end{array}$ & $\begin{array}{l}\text { Aesthetics } \\
\text { (mean score) }\end{array}$ & Information (mean score) & App quality (mean score) \\
\hline $\begin{array}{l}\text { 1. SOFA-Sepsis-related Organ Failure } \\
\quad \text { Assessment }\end{array}$ & 3.88 & 2.67 & 2.17 & 2.88 \\
2. Apache II Score & 3.5 & 3.33 & 2.5 & 3.16 \\
3. SOFA & 4.38 & 4.17 & 3 & 3.74 \\
4. SOFA Score & 4.38 & 4.17 & 3.83 & 3.95 \\
5. SAPS 3 Calc & 3.5 & 3.33 & 4 & 3.58 \\
6. Sepsis Score: SOFA Calculator & 4.75 & 3.67 & 3.38 & 3.8 \\
\hline
\end{tabular}


Table 1 (continued)

Descriptive characteristics

\begin{tabular}{|c|c|c|c|c|}
\hline Name of apps & $\begin{array}{l}\text { Functionality } \\
\text { (mean score) }\end{array}$ & $\begin{array}{l}\text { Aesthetics } \\
\text { (mean score) }\end{array}$ & Information (mean score) & App quality (mean score) \\
\hline 7. qSOFA Score calculator & 4.88 & 3.5 & 3.13 & 3.68 \\
\hline 8. qSOFA Score Calculator & 4.5 & 2.5 & 2.5 & 3.18 \\
\hline 9. SOFA score & 4.88 & 3.5 & 2.5 & 3.54 \\
\hline 10. MEWS (Modified Early Warning Score) & 3.88 & 2.33 & 2.33 & 2.79 \\
\hline 11. NEWS2 Chart & 3.13 & 2.33 & 2.33 & 2.65 \\
\hline 12. NEWS score & 3.5 & 2.33 & 2.33 & 2.72 \\
\hline $\begin{array}{l}\text { 13. NEWS 2-National Early Warning Score } \\
2017\end{array}$ & 3.5 & 2.33 & 2.33 & 2.72 \\
\hline 14. Observation-NEWS 2 & 5 & 5 & 4.88 & 4.64 \\
\hline 15. RRAPID & 4.13 & 2 & 2.13 & 2.69 \\
\hline 16. MEWS & 4.75 & 3.5 & 1.75 & 3.23 \\
\hline 17. NEWS Wales & 3.133 .13 & 2.832 .5 & 2.582 .25 & 2.842 .67 \\
\hline 18. Medical Formulas & 3.88 & 3.83 & 4.5 & 3.95 \\
\hline 19. EP Mobile & 3.5 & 3.33 & 4 & 3.58 \\
\hline 20. MedCal Lite Fastest Medical Calculator & 4.13 & 3.83 & 4.5 & 4.09 \\
\hline 21. Nursing Calculator & 3.88 & 3.17 & 3 & 3.24 \\
\hline 22. Nursing & 3.38 & 3.33 & 3.33 & 3.36 \\
\hline 23. Doctor Calci & 4.75 & 4.33 & 4.5 & 4.3 \\
\hline 24. Medical Calculators & 4.63 & 4.33 & 4.33 & 4.4 \\
\hline 25. NEWS \& SEPSIS SCREENING & 3.88 & 4 & 4.17 & 3.89 \\
\hline 26. Calculate by QxMD & 4.75 & 3.67 & 3.83 & 3.96 \\
\hline 27. Coly ICU & 4.75 & 4 & 4.33 & 4.1 \\
\hline 28. 3C Critical Care Calculators & 4.88 & 3.83 & 3.17 & 3.82 \\
\hline 29. MDCalc Medical Calculator & 4.88 & 4.83 & 5 & 4.75 \\
\hline 30. MediCalc $\AA$ & 5 & 4.33 & 5 & 4.61 \\
\hline 31. SEPSIS 3 & 5 & 4.33 & 5 & 4.56 \\
\hline 32. Sepsis Clinical Guide & 4.38 & 4.33 & 4.33 & 4.24 \\
\hline 33. NCalc & 4.13 & 3.17 & 2.5 & 3.17 \\
\hline $\begin{array}{l}\text { MOS }=\text { mobile operating system; } \\
\text { AND }=\text { Android }\end{array}$ & $4.25-0.62$ & $3.53-0.77$ & $3.51-1.07$ & $3.66-0.65$ \\
\hline
\end{tabular}

potential differences in predictions for in-hospital versus 30-day mortality.

In addition, there was a wide variety of clinical variables that were used as predictors of mortality in SOFA-based apps, which was particularly relevant to the respiratory and cardiovascular organ systems. For example, when classifying respiratory function, $\mathrm{PaO}_{2} / \mathrm{FiO}_{2}$ can be classified individually as the Carrico index or separately. From the perspective of the healthcare professional end user, this can be confusing and a barrier to clinical utility [70].

Smartphone app stores, like Google Play Store and App Store, should consider adding additional review criteria to include a rating for the scientific information quality of apps. The United Kingdom National Health Service [71] uses a publicly available app review service, Organization for the Review of Care and Health Applications [72], where users can find a list of healthcare apps that have been evaluated by healthcare professionals.

Future research should focus specifically on which apps are most applicable for patients with COVID-19. Paradoxically, among patients with COVID-19 in-hospital deaths are associated with low SOFA scores [17, 73, 74]. As such, MPM apps should include relevant laboratory values such as D-dimer and neutrophil to lymphocyte ratio [75-80], to better predict ICU mortality risk for patients with COVID-19. These findings are consistent with recent COVID-19 clinical trials, which also used SOFA and APACHE II most frequently [17, 74, 75, 81-83]. Some pandemic triage plans and protocols [84-86] 
Fig. 2 Distribution of mortality prediction model in evaluated apps. The "Other" category includes MPMs that were included only once (i.e., APACHE III, APACHE IV, ICD mortality risk score, mSOFA, REMS, SAPS III, SIRS, and Sepsis Assessment)
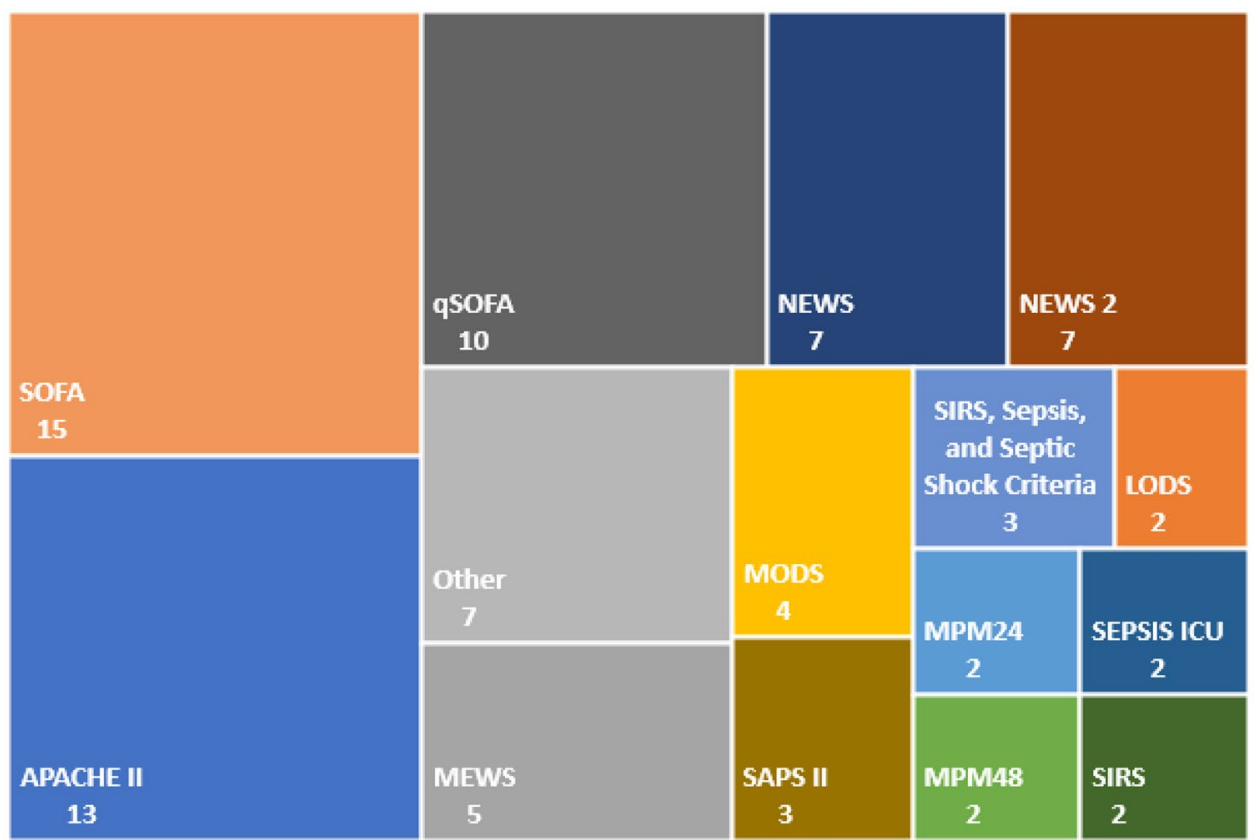

recommend the use of SOFA MPMs for diagnosis and management of COVID-19, while others do not [87].

A few important limitations are recognized in the study. Firstly, our two calculated vignettes based on the MIMIC III database may not represent patients who may or may not be at high or low-risk of mortality. For example, the high-risk patient vignette had a SOFA score of 18 but was not on mechanical ventilation, which most of the higher risk of ICU mortality patients are on. On the other hand, the mean SOFA calculated for lower-risk patient vignettes was similar to hospitalized COVID-19 patients [17, 74, 75, 81-83], who do have a high risk of mortality. A better solution for developing vignettes to evaluate the quality of the information provided by apps can be found in published papers where vignettes are based on the mean values of clinical parameters. A second limitation is that there are regional adaptations in the smartphone app stores, and, in this case, the search

Table 2 Single and multiple mortality prediction model calculators

\begin{tabular}{|c|c|c|c|c|c|c|c|c|c|c|c|c|c|c|c|c|c|}
\hline \multirow[t]{2}{*}{ MPMs in apps } & \multicolumn{17}{|c|}{ Single mortality prediction model calculators } \\
\hline & $\begin{array}{l}\text { App } \\
1\end{array}$ & $\begin{array}{l}\text { App } \\
2\end{array}$ & $\begin{array}{l}\text { App } \\
\mathbf{3}\end{array}$ & $\begin{array}{l}\text { App } \\
4\end{array}$ & $\begin{array}{l}\text { App } \\
5\end{array}$ & $\begin{array}{l}\text { App } \\
6\end{array}$ & $\begin{array}{l}\text { App } \\
7\end{array}$ & $\begin{array}{l}\text { App } \\
8\end{array}$ & $\begin{array}{l}\text { App } \\
9\end{array}$ & $\begin{array}{l}\text { App } \\
10\end{array}$ & $\begin{array}{l}\text { App } \\
11\end{array}$ & $\begin{array}{l}\text { App } \\
12\end{array}$ & $\begin{array}{l}\text { App } \\
13\end{array}$ & $\begin{array}{l}\text { App } \\
14\end{array}$ & $\begin{array}{l}\text { App } \\
15\end{array}$ & $\begin{array}{l}\text { App } \\
16\end{array}$ & $\begin{array}{l}\text { App } \\
17\end{array}$ \\
\hline 1. SOFA & $X$ & & $X$ & $X$ & & $X$ & & & $X$ & & & & & & & & \\
\hline 2. qSOFA & & & & & & & $\mathrm{X}$ & $\mathrm{X}$ & & & & & & & & & \\
\hline \multicolumn{18}{|l|}{ 3. mSOFA } \\
\hline 4. APACHE II & & $\mathrm{X}$ & & & & & & & & & & & & & & & \\
\hline \multicolumn{18}{|l|}{ 5. APACHE III } \\
\hline \multicolumn{18}{|l|}{ 6. APACHE IV } \\
\hline 7. NEWS & & & & & & & & & & & & $\mathrm{X}$ & & & $\mathrm{X}$ & & $\mathrm{X}$ \\
\hline 8. NEWS 2 & & & & & & & & & & & $\mathrm{X}$ & & $\mathrm{X}$ & $\mathrm{X}$ & & & \\
\hline 9. MEWS & & & & & & & & & & $\mathrm{X}$ & & & & & & $\mathrm{X}$ & \\
\hline \multicolumn{18}{|l|}{ 10. MODS } \\
\hline \multicolumn{18}{|l|}{ 11. SAPS II } \\
\hline 12. SAPS III & & & & & $\mathrm{X}$ & & & & & & & & & & & & \\
\hline \multicolumn{18}{|l|}{ 13. SSSSC } \\
\hline \multicolumn{18}{|l|}{ 14. SIRS } \\
\hline \multicolumn{18}{|l|}{ 15. SEPSIS-3 } \\
\hline \multicolumn{18}{|l|}{ 16. SIRS\&SA } \\
\hline 17. LODS & & & & & & & & & & & & & & & & & \\
\hline
\end{tabular}


Table 2 (Continued)

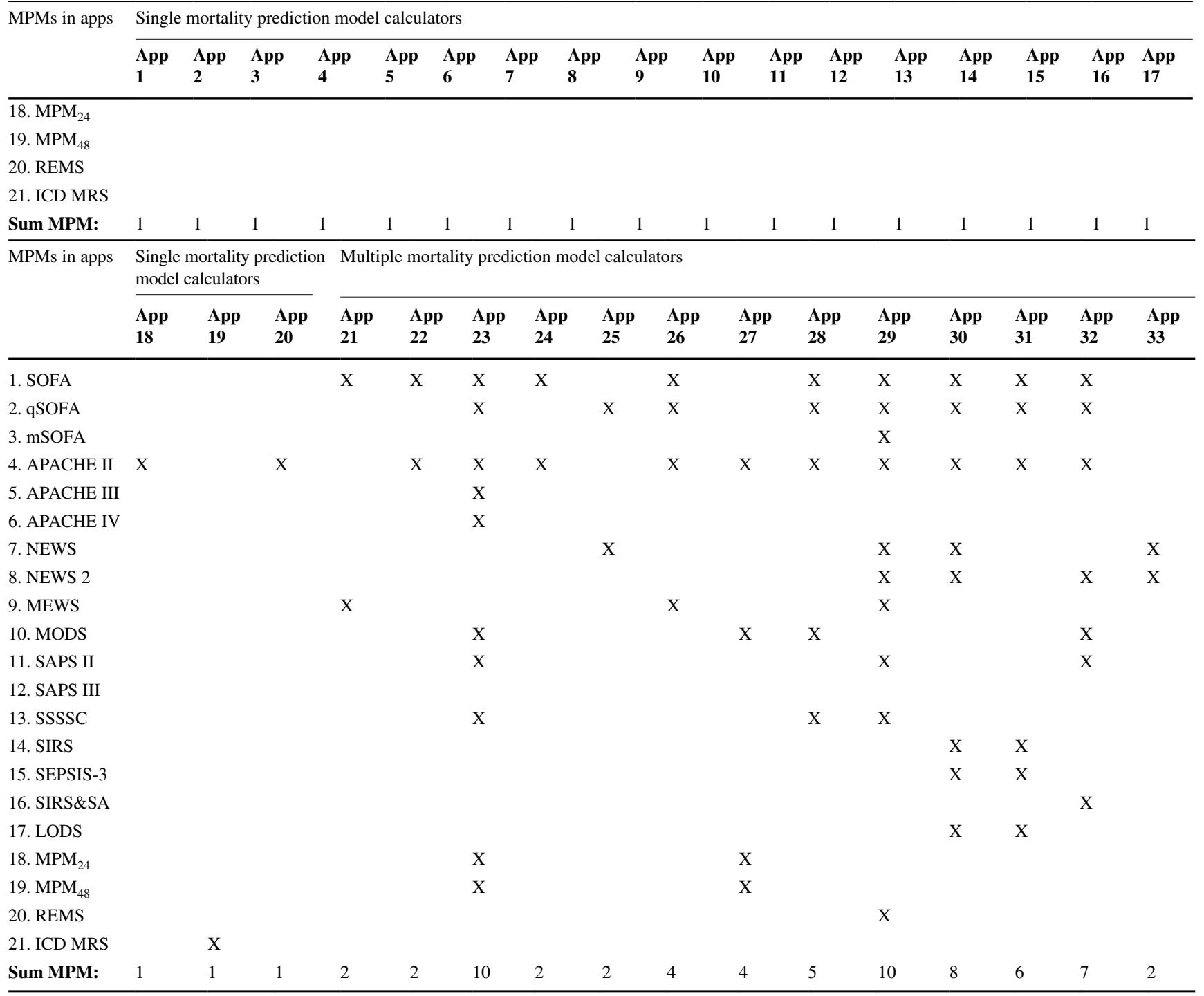

MPMs: Sequential Organ Failure Assessment (SOFA [11, 41, 47]), Quick SOFA (qSOFA) [48]), Modified SOFA (mSOFA [3]), Acute Physiology and Clinical Health Assessment (APACHE II-IV [49-52]), National Early Warning Score (NEW [53], NEWS2 [54], MEWS [55]), Multiple Organ Dysfunction Syndrome (MODS [56]), Simplified Acute Physiology Assessment (SAPS II-III [57-59]), Systemic Inflammatory Response Syndrome, Sepsis, and Septic Shock Criteria (SSSSC [60]), Systemic Inflammatory Response Syndrome (SIRS [61]), Third International Consensus Definitions for Sepsis and Septic Shock (SEPSIS-3 [62]), SIRS and Sepsis Assessment (SIRS\&SA [60]), Logistic Organ Dysfunction System (LODS [63]), Mortality Probability Model (MPM ${ }_{24,48}$ [64]), Rapid Emergency Medicine Score (REMS [65]), and ICD mortality risk score (ICD MRS [66])

was conducted using a European IP address so that it may have influenced the final set of apps obtained from the search engine. A potential bias of the review was the inclusion of freely available apps; however, this was a deliberate decision to represent available apps that do not pose a financial burden on the end-user, and are accessible to a wide audience of healthcare professionals, inclusive of low- and middle-income countries.
An important application of this work is for the education of healthcare professionals. Combining themes with vignettes based on simulation learning can increase student knowledge, critical thinking, and psychomotor skills for performing a better clinical evaluation of future patients [25]. For the next reviews, researchers should include specific medical calculator's apps because they provide relevant information. 


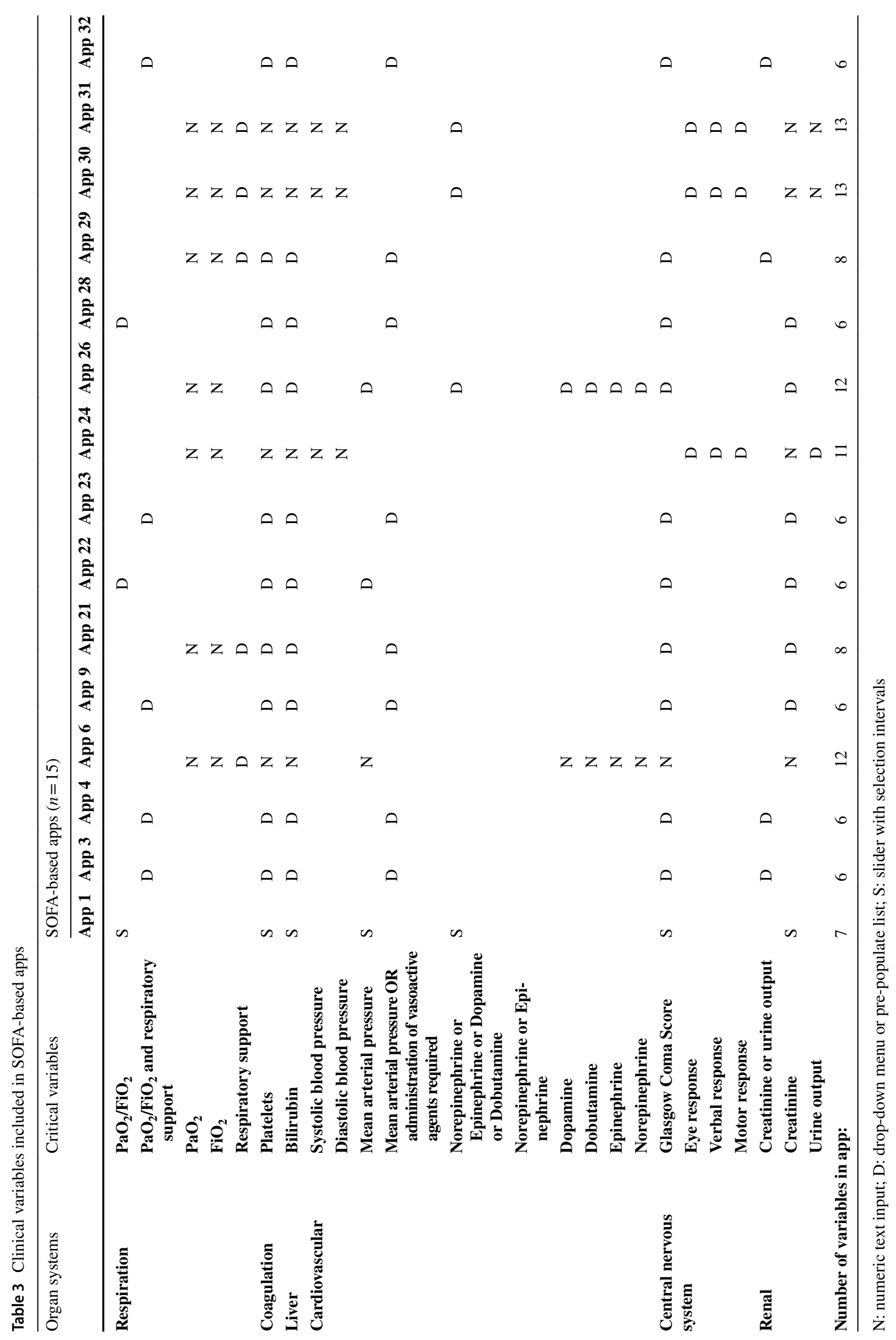


Table 4 Mean clinical values and SOFA scores for low and high-risk patient vignette

\begin{tabular}{|c|c|c|c|c|}
\hline Critical variables & $\begin{array}{l}\text { Mean values for low-risk } \\
\text { patient vignette }\end{array}$ & $\begin{array}{l}\text { SOFA points for low-risk } \\
\text { vignette }^{* *}\end{array}$ & $\begin{array}{l}\text { Mean values for high-risk } \\
\text { patient vignette }\end{array}$ & $\begin{array}{l}\text { SOFA points } \\
\text { for high-risk } \\
\text { vignette }\end{array}$ \\
\hline $\begin{array}{l}\mathbf{P a O}_{2} / \mathbf{F i O}_{2} \text { ratio } \\
\mathrm{PaO}_{2} \mathrm{mmHg} \\
\mathrm{FiO}_{2} \% \\
\text { Mechanical ventilation }\end{array}$ & $\begin{array}{l}\mathbf{3 0 8 . 2} \\
151 \\
49 \\
\text { No }\end{array}$ & +1 & $\begin{array}{l}\mathbf{2 2 9 . 3} \\
133 \\
58 \\
\text { No }\end{array}$ & +2 \\
\hline Platelets, $10^{9} / \mathrm{L}$ & 118.1 & +1 & 40.4 & +3 \\
\hline Bilirubin, g/L & 1.8 & +1 & 20 & +4 \\
\hline $\begin{array}{l}\text { Mean arterial pressure, } \mathbf{m m ~ H g} \\
\text { Systolic blood pressure, } \mathrm{mm} \mathrm{Hg} \\
\text { Diastolic blood pressure, } \mathrm{mm} \mathrm{Hg} \\
\text { Vasopressors }\end{array}$ & $\begin{array}{l}73 \\
110 \\
55 \\
\text { No }\end{array}$ & $\mathbf{0}$ & $\begin{array}{l}\mathbf{5 3} \\
82 \\
38 \\
\text { Dopamine }>5 \\
\text { or Epinephrine }>0.1 \\
\text { or Norepinephrine }>0.1\end{array}$ & +3 \\
\hline $\begin{array}{l}\text { Glasgow coma scale } \\
\text { Best eye response } \\
\text { Best verbal response } \\
\text { Best motor response }\end{array}$ & $\begin{array}{l}12 \\
3 \\
4 \\
5\end{array}$ & +2 & $\begin{array}{l}\mathbf{8} \\
3 \\
2 \\
3\end{array}$ & +3 \\
\hline $\begin{array}{l}\text { Creatinine } \\
\text { Urine output, } \mathrm{mL} / \text { day }\end{array}$ & $\begin{array}{l}1.3 \\
2900\end{array}$ & +1 & $\begin{array}{l}3.8 \\
250\end{array}$ & +3 \\
\hline Total SOFA points & & 6 points & & 18 points \\
\hline
\end{tabular}

*Average number was calculated using MIMIC III database; ${ }^{* *}$ SOFA points were calculated using original SOFA publication [41]

Table 5 SOFA score and percent of mortality in SOFAbased apps

\begin{tabular}{|c|c|c|c|c|c|}
\hline & \multirow[t]{2}{*}{ Short name } & \multicolumn{2}{|c|}{$\begin{array}{l}\text { Low mortality risk patient } \\
\text { vignette }\end{array}$} & \multicolumn{2}{|c|}{$\begin{array}{l}\text { High mortality risk patient } \\
\text { vignette }\end{array}$} \\
\hline & & SOFA score & $\%$ of mortality & SOFA score & $\%$ of mortality \\
\hline \multirow[t]{15}{*}{ SOFA-based apps $(n=15)$} & App 1 & 6 & N/A & 18 & N/A \\
\hline & App 3 & 6 & $<10 \%$ & 18 & $>90 \%$ \\
\hline & App 4 & 6 & $<10 \%$ & 18 & $>90 \%$ \\
\hline & App 6 & 6 & $<10 \%$ & 18 & $>90 \%$ \\
\hline & App 9 & 6 & N/A & 18 & N/A \\
\hline & App 21 & 6 & N/A & 18 & N/A \\
\hline & App 22 & 6 & N/A & 18 & N/A \\
\hline & App 23 & 6 & $<10 \%$ & 18 & $>90 \%$ \\
\hline & App 24 & 6 & N/A & 18 & N/A \\
\hline & App 26 & 6 & N/A & 18 & N/A \\
\hline & App 28 & 6 & $<10 \%$ & 18 & $>90 \%$ \\
\hline & App 29 & 6 & $<33 \%$ & 18 & $>95 \%$ \\
\hline & App 30 & 6 & $<33 \%$ & 18 & $95 \%$ \\
\hline & App 31 & 6 & $<33 \%$ & 18 & $95 \%$ \\
\hline & App 32 & 6 & $22 \%$ & 18 & $95 \%$ \\
\hline
\end{tabular}

N/A: The score was calculated but not the $\%$ of mortality

\section{Conclusion}

There is pressing urgency in ICU environments globally for accurate mortality risk prediction. Results from this systematic review support the overall quality and information quality of the MDCalc Medical Calculator for in-hospital mortality risk prediction. The benefits of MDCalc Medical Calculator are that it was developed to be used by healthcare professionals for critically ill adult ICU patients, it is available on both Android and iOS platforms, free, uses validated mortality prediction models, includes high-quality information MPMs, has less 
time-consuming methods for data entry, includes metric and imperial units, and is regularly updated. The MDCalc and Calculate by $Q x M D$ webpages also provide separate COVID-19 smartphone-based MPM calculators, which can be used when atypical physical spaces in healthcare systems are being used as make-shift ICUs. Smartphone MPMs can also be used for non-ICU patients to estimate time to potential clinical deterioration [88], or for triaging an ICU patient for palliative care services [86, 89].

\begin{abstract}
Authors' contributions The evaluation presented here was carried out in collaboration with all authors. NF developed a study design and supervised the study. NF, LC, and RMC drafted the manuscript. NF, LG, GS, and PK conducted data collection and analysis. PC interpreted results from a medical point of view. RMC conducted a comprehensive content review. All authors read, revised, and approved the final manuscript.
\end{abstract}

Funding This work was supported by the Slovenian Research Agency grant numbers N2-0101, P2-0057, and from the European Commissionfunded Erasmus + project Digital Toolbox for Innovation In Nursing Education (I-BOX), grant number 2019-1-ES01-KA203-065836. We also acknowledge funding for RMC through NIH/NINR (grant number R00NR016275)

\section{Declarations}

Conflicts Of interest/Competing interests None declared.

\section{References}

1. Vincent JL (2013) Critical care - where have we been and where are we going? Critical care 17(Suppl 1):1-6. https://doi.org/10. $1186 / \mathrm{cc} 11500$

2. Jain A, Palta S, Saroa R, Palta A, Sama S, Gombar S (2016) Sequential organ failure assessment scoring and prediction of patient's outcome in Intensive Care Unit of a tertiary care hospital. J Anaesthesiol Clin Pharmacol 32(3):364-368. https://doi.org/10. 4103/0970-9185.168165

3. Grissom CK, Brown SM, Kuttler KG, Boltax JP, Jones J, Jephson AR, Orme JF (2010) A modified sequential organ failure assessment score for critical care triage. Disaster Med Public Health Prep 4:277-284. https://doi.org/10.1001/dmp.2010.404

4. Rapsang AG, Shyam DC (2014) Scoring systems in the intensive care unit: A compendium. Indian J Crit Care Med 18:220 228. https://doi.org/10.4103/0972-5229.130573

5. Johnson S, Saranya A (2015) Comparison of Different Scoring Systems Used in the Intensive Care Unit. J Pulm Respir Med 5:2. https://doi.org/10.4172/2161-105X.1000276

6. Penoyer DA (2010) Nurse staffing and patient outcomes in critical care: A concise review. Crit Care Med 38:1521-1528. https://doi. org/10.1097/CCM.0b013e3181e47888

7. Afshar M, Arain E, Ye C, Gilbert E, Xie M, Lee J, Churpek MM, Durazo-Arvizu R, Markossian T, Joyce C (2019) Patient Outcomes and Cost-Effectiveness of a Sepsis Care Quality Improvement Program in a Health System. Crit Care Med 47:13711379. https://doi.org/10.1097/CCM.0000000000003919

8. Edbrooke DL, Minelli C, Mills GH, Iapichino G, Pezzi A, Corbella D, Jacobs P, Lippert A, Wiis J, Pesenti A, Patroniti N
(2011) Implications of ICU triage decisions on patient mortality: A cost-effectiveness analysis. Crit Care 15:1-9. https://doi.org/ $10.1186 / \mathrm{cc} 10029$

9. Glance LG, Osler T, Shinozaki T (1998) Intensive care unit prognostic scoring systems to predict death: a cost-effectiveness analysis. Crit Care Med 26:1842-1849. https://doi.org/10.1097/00003246199811000-00026

10. Dehghani A, Abdeyazdan G, Davaridolatabadi E (2016) An Overview of the Predictor Standard Tools for Patient Weaning from Mechanical Ventilation. Electronic physician 8:1955-1963. https://doi.org/10.19082/1955

11. Lambden S, Laterre PF, Levy MM, Francois B (2019) The SOFA score - Development, utility and challenges of accurate assessment in clinical trials. Crit Care 23:1-9. https://doi.org/10.1186/ s13054-019-2663-7

12. Jain A, Palta S, Saroa R, Palta A, Sama S, Gombar S (2016) Sequential organ failure assessment scoring and prediction of patient's outcome in Intensive Care Unit of a tertiary care hospital. J Anaesthesiol Clin Pharmacol 32:364. https://doi.org/10. 4103/0970-9185.168165

13. Jones AE, Trzeciak S, Kline JA (2009) The Sequential Organ Failure Assessment score for predicting outcome in patients with severe sepsis and evidence of hypoperfusion at the time of emergency department presentation. Crit Care Med 37:16491654. https://doi.org/10.1097/CCM.0b013e31819def97

14. Goodwin AJ (2019) Can Serial qSOFA Measurement Aid in Sepsis Identification and Triage Decisions?. Critical care medicine 46:2046-2048. https://doi.org/10.1097/CCM.0000000000003417

15. Kim Y, Kim K, Jang I (2019) Analysis of mortality prognostic factors using model for end-stage liver disease with incorporation of serum-sodium classification for liver cirrhosis complications: A retrospective cohort study. Medicine (Baltimore) 98(45):e17862. https://doi.org/10.1097/MD.0000000000017862

16. Sekulic AD, Trpkovic S V., Pavlovic AP, Marinkovic OM, Ilic AN (2015) Scoring Systems in Assessing Survival of Critically Ill ICU Patients. Med Sci Monit 21:2621-2629. https://doi.org/ 10.12659/MSM.894153

17. Yang X, Yu Y, Xu J, Shu H, Xia J, Liu H, Wu Y, Zhang L, Yu Z, Fang M, Yu T, Wang Y (2020) Clinical course and outcomes of critically ill patients with SARS-CoV-2 pneumonia in Wuhan, China: a singlecentered, retrospective, observational study. Lancet Respir Med. Elsevier Ltd 8:475-481. https://doi.org/10.1016/S2213-2600(20)30079-5

18. Collins SA, Cato K, Albers D, Scott K, Stetson PD, Bakken S, Vawdrey DK (2013) Relationship between nursing documentation and patients' mortality. American Journal of Critical Care 22:30613. https://doi.org/10.4037/ajcc2013426

19. Goldstein BA, Navar AM, Pencina MJ, Ioannidis JPA (2016) Opportunities and challenges in developing risk prediction models with electronic health records data: a systematic review. Journal of the American Medical Informatics Association 24:198208. https://doi.org/10.1093/jamia/ocw042

20. Moons KGM, Royston P, Vergouwe Y, Grobbee DE, Altman DG (2009) Prognosis and prognostic research: what, why, and how ? BMJ 338:B375. https://doi.org/10.1136/bmj.b375

21. Wyatt JC, Altman DG (1995) Commentary: Prognostic models: clinically useful or quickly forgotten? BMJ 311:15391541. https://doi.org/10.1136/bmj.311.7019.1539

22. Hollander JE, Carr BG (2020) Virtually Perfect? Telemedicine for Covid-19. N Engl J Med 382:1679-1681. https://doi.org/10.1056/ NEJMp2003539

23. Khera R, Jain S, Lin Z, Ross JS, Krumholz H (2020) Evaluation of the Anticipated Burden of COVID-19 on Hospital-Based Healthcare Services Across the United States. medRxiv. https:// doi.org/10.1101/2020.04.01.20050492

24. Martínez-Pérez B, de la Torre-Díez I (2014) Mobile Clinical Decision Support Systems and Applications : A Literature and 
Commercial Review. Journal of medical systems 38:4. https://doi. org/10.1007/s10916-013-0004-y

25. Iorio-Morin C, Fortin D, Blanchard J (2016) TBI prognosis calculator: A mobile application to estimate mortality and morbidity following traumatic brain injury. Clin Neurol Neurosurg 142:4853. https://doi.org/10.1016/j.clineuro.2016.01.021

26. Cohen AB, Nahed BV, Sheth KN (2013) Mobile medical applications in neurology. Neurol Clin Pr 3:52-60. https://doi.org/10. 1212/CPJ.0b013e318283ff4f

27. Choi W, Park MA, Hong E, Kim S, Ahn R, Hong J, Song S, Kim T, Kim J, Yeo S (2013) Development of mobile electronic health records application in a secondary general hospital in Korea. Healthc Inform Res 19:307-313. https://doi.org/10.4258/hir.2013. 19.4.307

28. Hansen C, Sanchez-Ferro A, Maetzler W (2018) How mobile health technology and electronic health records will change care of patients with Parkinson's disease. J Parkinsons Dis 8:S41S45. https://doi.org/10.3233/JPD-181498

29. Choi W, Park M, Hong E, Kim S, Ahn R, Hong J, Song S, Kim T, Kim J, Yeo S (2015) Early experiences with mobile electronic health records application in a tertiary hospital in Korea. Healthc Inform Res 21:292-298. https://doi.org/10.4258/hir.2015.21.4.292

30. Peters AW , Chawla KS, Turnbull ZA (2020) Transforming ORs into ICUs. N Engl J Med, 382(19): p.e52. https://doi.org/10.1056/ NEJMc2010853

31. Carmona MJ, Quintão VC, Melo BF, André RG, Kayano RP, Perondi B, Miethke-Morais A, Rocha MC, Malbouisson LM, Auler-Júnior JO (2020) Transforming operating rooms into intensive care units and the versatility of the physician anesthesiologist during the COVID-19 crisis. Clinics, 12(75): e2023. https://doi.org/10.6061/clinics/2020/ e2023

32. Qiu H, Tong Z, Ma P, Hu M, Peng Z, Wu W, Du B (2020) Intensive care during the coronavirus epidemic. Intensive Care Med 46:576-578. https://doi.org/10.1007/s00134-020-05966-y

33. Pan L, Wang L, Huang X (2020) How to face the novel coronavirus infection during the $2019-2020$ epidemic : the experience of Sichuan Provincial People's Hospital. Intensive Care Med 46:573-575. https://doi.org/10.1007/s00134-020-05964-0

34. Liao X, Wang B, Kang Y (2020) Novel coronavirus infection during the 2019 - 2020 epidemic : preparing intensive care units - the experience in Sichuan Province, China. Intensive Care Med 46:357-360. https://doi.org/10.1007/s00134-020-05954-2

35. Polit DF, Beck CT (2009) Essentials of Nursing Research: Appraising Evidence for Nursing Practice. Lippincott Williams \& Wilkins

36. Moher D, Liberati A, Tetzlaff J, Altman DG, The PRISMA Group (2009) Preferred reporting items for systematic reviews and meta-analyses: the PRISMA statement. PLoS Med 6:e1000097. https://doi.org/10.1371/journal.pmed.1000097

37. iPadian Premium - The Best iOS and iPad simulator. https://ipadian. net/. Accessed 10 August 2020

38. Stoyanov SR, Hides L, Kavanagh DJ, Wilson H (2016) Development and Validation of the User Version of the Mobile Application Rating Scale (uMARS). JMIR mHealth uHealth 4:e72. https://doi. org/10.2196/mhealth.5849

39. Team RC (2013) R version 3.6. 0. R: A language and environment for statistical computing. R Foundation for Statistical Computing, Vienna. https://doi.org/10.1002/nur.21990

40. Johnson AEW, Pollard TJ, Shen L, Lehman LH, Feng M, Ghassemi M, Moody B, Szolovits P, Celi LA, Mark RG (2016) MIMIC-III , a freely accessible critical care database. Scientific data 3:1-9. https:// doi.org/10.1038/sdata.2016.35

41. Vincent JL, Moreno R, Takala J, Willatts S, De Mendonça A, Bruining H, Reinhart CK, Suter P, Thijs LG (1996) The SOFA (Sepsis-related Organ Failure Assessment) score to describe organ dysfunction/failure. Intensive Care Med 22(7):707-10. https://doi. org/10.1007/BF01709751

42. Adam A, Hellig JC, Perera M, Bolton D, Lawrentschuk N (2018) 'Prostate Cancer Risk Calculator'mobile applications (Apps): a systematic review and scoring using the validated user version of the Mobile Application Rating Scale (uMARS). World Journal of Urology. Apr;36(4):565-73. https://doi.org/10.2196/mhealth. 5882

43. Bardus M, Ali A, Demachkieh F, Hamadeh G (2019) Assessing the quality of mobile phone apps for weight management: Usercentered study with employees from a Lebanese university. JMIR mHealth uHealth 7: e9836. https://doi.org/10.2196/mhealth.9836

44. Li Y, Ding J, Wang Y, Tang C, Zhang P (2019) Nutrition-related mobile apps in the China App Store: Assessment of functionality and quality. JMIR mHealth uHealth 7:e13261. https://doi.org/10. $2196 / 13261$

45. Fijačko N, Gosak L, Cilar L, Novšak A, Creber RM, Skok P, Štiglic G (2019) The Effects of Gamification and Oral Self-Care on Oral Hygiene in Children: Systematic Search in App Stores and Evaluation of Apps . JMIR mHealth uHealth 8:e16365. https://doi. org/10.2196/16365

46. Lebeau K, Huey LG, Hart M (2019) Assessing the quality of mobile apps used by occupational therapists: Evaluation using the user version of the mobile application rating scale. JMIR mHealth uHealth 7:e13019. https://doi.org/10.2196/13019

47. Pettilä V (2002) Sequential assessment of multiple organ dysfunction as a predictor of outcome. JAMA 287:713-714. https://doi. org/10.1001/jama.287.6.711

48. Seymour CW, Liu VX, Iwashyna TJ, Brunkhorst FM, Rea TD, Scherag A, Rubenfeld G, Kahn JM, Shankar-Hari M, Singer M, Deutschman CS (2016) Assessment of clinical criteria for sepsis for the third international consensus definitions for sepsis and septic shock (sepsis-3). JAMA 315:762-774. https://doi.org/10. 1001/jama.2016.0288

49. Knaus WA, Draper EA, Wagner DP, Zimmerman JE (1985) APACHE II: a severity of disease classification system. Crit Care Med 13(10):818-829. https://doi.org/10.1097/00003465198603000-00013

50. Knaus WA, Wagner DP, Draper EA, Zimmerman JE, Bergner M, Bastos PG, Sirio CA, Murphy DJ, Lotring T, Damiano A, Harrell Jr FE (1991) The APACHE III prognostic system: Risk prediction of hospital mortality for critically III hospitalized adults. Chest 100:1619-1636. https://doi.org/10.1378/chest.100.6.1619

51. Knaus WA, Zimmerman JE, Wagner DP, Draper EA, Lawrence DE (1981) APACHE-acute physiology and chronic health evaluation: a physiologically based classification system. Crit Care Med 9:591-597. https://doi.org/10.1097/00003246-198108000-00008

52. Zimmerman JE, Kramer AA, McNair DS, Malila FM (2006) Acute Physiology and Chronic Health Evaluation (APACHE) IV: Hospital mortality assessment for today's critically ill patients. Crit Care Med 34:1297-1310. https://doi.org/10.1097/01.CCM. 0000215112.84523.F0

53. Smith GB, Prytherch DR, Meredith P, Schmidt PE, Featherstone PI. The ability of the National Early Warning Score (NEWS) to discriminate patients at risk of early cardiac arrest, unanticipated intensive care unit admission, and death. Resuscitation 84:465470. https://doi.org/10.1016/j.resuscitation.2012.12.016

54. Raoyal College of Physicians (2017) National Early Warning Score (NEWS) 2. https://www.rcplondon.ac.uk/projects/outputs/ national-early-warning-score-news-2 Accessed 10 August 2020

55. Subbe CP, Kruger M, Rutherford P, Gemmel L (2001) Validation of a modified early warning score in medical admissions. QJM 94:521-526. https://doi.org/10.1093/qjmed/94.10.521

56. Marshall JC, Cook DJ, Christou NV, Bernard GR, Sprung CL, Sibbald WJ (1995) Multiple organ dysfunction score: a reliable descriptor of a 
complex clinical outcome. Crit Care Med 23(10):1638-1652. https:// doi.org/10.1097/00003246-199510000-00007

57. Le Gall JR, Loirat P, Alperovitch A, Glaser P, Granthil C, Mathieu D, Mercier P, Thomas R, Villers D (1984) A simplified acute physiology score for ICU patients. Crit Care Med 12:975-977. https://doi. org/10.1097/00003246-198411000-00012

58. Moreno RP, Metnitz PGH, Almeida E, Jordan B, Bauer P, Campos RA, Iapichino G, Edbrooke D, Capuzzo M, Le Gall JR, SAPS 3 Investigators (2005) SAPS 3 - From evaluation of the patient to evaluation of the intensive care unit. Part 2: Development of a prognostic model for hospital mortality at ICU admission. Intensive Care Med 31:1345-1355. https://doi.org/10.1007/s00134-005-2763-5

59. Le Gall JR, Lemeshow S, Saulnier F (1993) A new Simplified Acute Physiology Score (SAPS II) based on a European/North American multicenter study. Jama 270:2957-2963. https://doi.org/ 10.1001/jama.270.24.2957

60. Bone RC, Balk RA, Cerra FB, Dellinger RP, Fein AM, Knaus WA, Schein RM, Sibbald WJ (1992) Definitions for sepsis and organ failure and guidelines for the use of innovative therapies in sepsis. Chest 101:1644-1655. https://doi.org/10.1378/chest.101.6.1644

61. Balk RA (2014) Systemic inflammatory response syndrome (SIRS): Where did it come from and is it still relevant today? Virulence 5:20-26. https://doi.org/10.4161/viru.27135

62. Singer M, Deutschman CS, Seymour C, Shankar-Hari M, Annane D, Bauer M, Bellomo R, Bernard GR, Chiche JD, Coopersmith CM, Hotchkiss RS (2016) The third international consensus definitions for sepsis and septic shock (sepsis-3). JAMA 315:801-810. https://doi. org/10.1001/jama.2016.0287

63. Le Gall JR, Klar J, Lemeshow S, Saulnier F, Alberti C, Artigas A, Teres D (1996) The Logistic Organ Dysfunction system: a new way to assess organ dysfunction in the intensive care unit. Jama 276:802-810. https://doi.org/10.1001/jama.276.10.802

64. Lemeshow S, Teres D, Klar J, Avrunin JS, Gehlbach SH, Rapoport J (1993) Mortality Probability Models (MPM II) based on an international cohort of intensive care unit patients. Jama 270:2478-2486. PMID: 8230626

65. Olsson T, Terent A, Lind L (2004) Rapid Emergency Medicine Score can predict long-term mortality in nonsurgical emergency department patients. Acad Emerg Med 11(10):1008-1013. https:// doi.org/10.1197/j.aem.2004.05.027

66. Providência R, Boveda S, Lambiase P, Defaye P, Algalarrondo V, Sadoul N, Piot O, Klug D, Perier MC, Bouzeman A, Gras D (2015) Prediction of nonarrhythmic mortality in primary prevention implantable cardioverter-defibrillator patients with ischemic and nonischemic cardiomyopathy. JACC Clin Electrophysiol 1:29-37. https://doi.org/10.1016/j.jacep.2015.01.004

67. Zapata BC, Fernández-Alemán JL, Idri A, Toval A (2015) Empirical Studies on Usability of mHealth Apps: A Systematic Literature Review. J Med Syst 39:1-19. https://doi.org/10.1007/s10916-014-0182-2

68. Collado-Borrell R, Escudero-Vilaplana V, Ribed-Sánchez A, IbáñezGarcía S, Herranz-Alonso A, Sanjurjo-Sáez M (2016) Smartphone applications for cancer patients; what we know about them? Farm Hosp 40:25-35. https://doi.org/10.7399/fh.2016.40.1.8993

69. Fijacko N, Brzan PP, Stiglic G (2015) Mobile Applications for Type 2 Diabetes Risk Estimation: a Systematic Review. J Med Syst 39:124. https://doi.org/10.1007/s10916-015-0319-y

70. Sillence E, Briggs P, Harris PR, Fishwick L (2007) How do patients evaluate and make use of online health information? Soc Sci Med 64:1853-1862. https://doi.org/10.1016/j.socscimed.2007.01.012

71. NHS. https://www.nhs.uk/. Accessed 10 August 2020

72. ORCHA. https://www.orcha.co.uk/. Accessed 10 August 2020

73. Weiss P, Murdoch DR (2020). Clinical course and mortality risk of severe COVID-19. Lancet 395:1014-1015. https://doi.org/10. 1016/S0140-6736(20)30633-4

74. Zhang G, Hu C, Luo L, Fang F, Chen Y, Li J, Peng Z, Pan H (2020) Clinical features and short-term outcomes of 221 patients with
COVID-19 in Wuhan, China. J Clin Virol 127:104364. https:// doi.org/10.1016/j.jcv.2020.104364

75. Zhou F, Yu T, Du R, Fan G, Liu Y, Liu Z, Xiang J, Wang Y, Song B, Gu X, Guan L (2020) Clinical course and risk factors for mortality of adult inpatients with COVID-19 in Wuhan, China: a retrospective cohort study. Lancet 395:1054-1062. https://doi. org/10.1016/S0140-6736(20)30566-3

76. Yan L, Zhang H-T, Goncalves J, Xiao Y, Wang M, Guo Y, Sun C, Tang X, Jin L, Zhang M, Huang X. A machine learning-based model for survival prediction in patients with severe COVID-19 infection. medRxiv 2020. https://doi.org/10.1101/2020.02.27.20028027

77. Lu J, Hu S, Fan R, Liu Z, Yin X, Wang Q, Lv Q, Cai Z, Li H, Hu Y, Han Y (2020) ACP risk grade: a simple mortality index for patients with confirmed or suspected severe acute respiratory syndrome coronavirus 2 disease (COVID-19) during the early stage of outbreak in Wuhan, Chin. https://doi.org/10.1101/2020.02.20.20025510

78. Qin C, Zhou L, Hu Z, Zhang S, Yang S, Tao Y, Xie C, Ma K, Shang K, Wang W, Tian DS (2020) Dysregulation of immune response in patients with COVID-19 in Wuhan, China. Clin Infect Dis 71:762-768. https://doi.org/10.1093/cid/ciaa248

79. Lagunas-Rangel FA (2020) Neutrophil-to-lymphocyte ratio and lymphocyte-to-C-reactive protein ratio in patients with severe coronavirus disease 2019 (COVID-19): A meta-analysis. J Med Virol. 2020:1-2. https://doi.org/10.1002/jmv.25819

80. Liu Y, Du X, Chen J, Jin Y, Peng L, Wang HH, Luo M, Chen L, Zhao Y. Neutrophil-to-lymphocyte ratio as an independent risk factor for mortality in hospitalized patients with COVID-19. J Infect 81:e6-e12. https://doi.org/10.1016/j.jinf.2020.04.002

81. Worku B, Gaudino M, Avgerinos D, Ramasubbu K, Gambardella I, Gulkarov I, Khin S. A comparison of existing risk prediction models in patients undergoing venoarterial extracorporeal membrane oxygenation. Heart \& Lung. https://doi.org/10.1016/j.hrtlng.2020.03.004

82. Rello J, Tejada S, Userovici C, Arvaniti K, Pugin J, Waterer G (2020) Coronavirus Disease 2019 (COVID-19): A critical care perspective beyond China. Anaesth Crit Care Pain Med 39:167169. https://doi.org/10.1016/j.accpm.2020.03.001

83. Jin X, Pang B, Zhang J, Liu Q, Yang Z, Feng J, Liu X, Zhang L, Wang B, Huang Y, Fauci AJ. Core Outcome Set for Clinical Trials on Coronavirus Disease 2019 (COS-COVID). Engineering. https://doi.org/10.1016/j.eng.2020.03.002

84. Qiu R, Wei X, Zhao M, Zhong C, Zhao C, Hu J, Li M, Huang Y, Han S, He T, Chen J (2020) Outcome reporting from protocols of clinical trials of Coronavirus Disease 2019 (COVID-19): a review. medRxiv https://doi.org/10.1101/2020.03.04.20031401

85. Jamil S, Mark N, Carlos G, Cruz CSD, Gross JE, Pasnick S (2020) Diagnosis and Management of COVID-19 Disease. Am J Respir Crit Care Med 201:P19-P20. https://doi.org/10.1164/rccm.2020C1

86. Truog RD, Mitchell C, Daley GQ (2020) The toughest triageallocating ventilators in a pandemic. N Engl J Med 382:1969_ 1973. https://doi.org/10.1056/NEJMp2005689

87. Aziz S, Arabi YM, Alhazzani W, Evans L, Citerio G, Fischkoff K, Salluh J, Meyfroidt G, Alshamsi F, Oczkowski S, Azoulay E (2014) Managing ICU surge during the COVID-19 crisis: rapid guidelines. Intensive Care Med 46:1303-1325. https://doi.org/10.1007/ s00134-020-06092-5

88. Yu S, Leung S, Heo M, Soto GJ, Shah RT, Gunda S, Gong MN (2014) Comparison of risk prediction scoring systems for ward patients: A retrospective nested case-control study. Crit Care 18:R132. http://ccforum.com/content/18/3/R132

89. Arie S (2020) Covid-19: Can France's ethical support units help doctors make challenging decisions? BMJ 369:2-3. https://doi. org/10.1136/bmj.m1291

Publisher's Note Springer Nature remains neutral with regard to jurisdictional claims in published maps and institutional affiliations. 